\title{
Ketamine in Major Depressive Disorder: Mechanisms and Future Perspectives
}

\author{
Cheolmin Shin and Yong-Ku Kim ${ }^{凶}$ \\ Department of Psychiatry, Korea University Ansan Hospital, Korea University College of Medicine, Ansan, Republic of Korea
}

\begin{abstract}
Major depressive disorder (MDD) is a serious psychiatric illness that causes functional impairment in many people. While monoaminergic antidepressants have been used to effectively treat MDD, these antidepressants have limitations in that they have delayed onset of action and many patients remain treatment-resistant. Therefore, there is a need to develop antidepressants with a novel target, and researchers have directed their attention to the glutamatergic system. Ketamine, although developed as an anesthetic, has been found to produce an antidepressant effect at sub-anesthetic doses via N-Methyl-D-aspartic acid (NMDA) receptor blockade as well as NMDA receptor-independent pathways. A single infusion of ketamine produced rapid improvement in clinical symptoms to a considerable level and led to the resolution of serious depressive symptoms, including imminent suicidal ideation, in patients with MDD. A series of recent randomized controlled trials have provided a high level of evidence for the therapeutic efficacy of ketamine treatment in MDD and presented new insights on the dose, usage, and route of administration of ketamine as an antidepressant. With this knowledge, it is expected that ketamine treatment protocols for MDD will be established as a treatment option available in clinical practice. However, long-term safety must be taken into consideration as ketamine has abuse potential and it is associated with psychological side effects such as dissociative or psychotomimetic effects.

Psychiatry Investig 2020;17(3):181-192
\end{abstract}

Key Words Ketamine, Major depressive disorder, Antidepressant, N-Methyl-D-aspartic acid (NMDA) receptor antagonist.

\section{INTRODUCTION}

The prevalence of major depressive disorder (MDD) worldwide is estimated to be $5 \%,{ }^{1}$ and, in addition to being a disabling disorder, it also has a serious impact on health by increasing suicide risk and mortality risk from cardiovascular and cerebrovascular diseases. ${ }^{2}$ MDD generally assumes a chronic course and causes functional impairment due to frequent relapse after remission. Although effective treatment methods are available, there are some limitations to these treatments. Some patients do not experience alleviation of symptoms despite several trials of adequate psychopharmacological and psychological therapy. Insufficiently treated depression results in the burden of residual symptoms and inflated risk for subsequent recurrence or overt treatment-

Received: September 10, 2019 Revised: October 27, 2019

Accepted: November 18, 2019

$\triangle$ Correspondence: Yong-Ku Kim, MD, PhD

Department of Psychiatry, College of Medicine, Korea University, Ansan Hospital, 123 Jeokgeum-ro, Danwon-gu, Ansan 15355, Republic of Korea

Tel: +82-31-412-5140, Fax: +82-31-412-5132, E-mail: yongku@korea.edu

(a) This is an Open Access article distributed under the terms of the Creative Commons Attribution Non-Commercial License (https://creativecommons.org/licenses/by$\mathrm{nc} / 4.0$ ) which permits unrestricted non-commercial use, distribution, and reproduction in any medium, provided the original work is properly cited. resistance depression (TRD). ${ }^{3}$ In addition, currently approved antidepressants generally take several weeks to produce an effect. Therefore, the need for a more effective and rapid-acting antidepressant is evident. ${ }^{4,5}$

In particular, these problems arise in pharmacotherapy because most of the antidepressants currently available target the monoamine system. First, although an overwhelming majority of antidepressants target the monoamine system, a relatively high proportion of patients have TRD despite pharmacotherapy. ${ }^{3}$ In the large-scale, Sequenced Treatment Alternatives to Relieve Depression Study conducted in the United States, as high as $46 \%$ of the patients did not respond to firstand second-line treatment with monoamine antidepressants, ${ }^{6}$ and the final remission rate was only $13 \%$ to $14 \%$ in patients who did not achieve remission when treated with the initial two antidepressants. ${ }^{3}$ The second problem is the delayed onset of the therapeutic effect of current antidepressants. In animal studies, serotonin and norepinephrine reuptake inhibitors induced an initial increase in neurotransmitters in mice within few hours or days of administration; however, improvement in key depressive symptoms was observed few weeks after the administration. ${ }^{7}$ Patients who received antidepressant treatment also exhibited actual improvement in 
symptoms after a given period after treatment. ${ }^{8-10}$ Monoamine antidepressants may take time to neurochemically desensitize through the administration of an antidepressant followed by a 5-HT1A autoreceptor that normally inhibits serotonin release at the nerve terminal. In another hypothesis, monoamine antidepressants can promote neuroplasticity but this function be delayed because such plasticity is achieved through complex cascades. ${ }^{11}$ Lastly, most of the current monoamine-modulating antidepressants carry side-effects of variable degrees, sometimes involving the therapeutic joint effects both in the acute- and long-term settings. ${ }^{12,13}$ Such limitations to the use of monoamines serve as a stimulus for the development of novel antidepressants with different mechanisms of action.

The development of antidepressants with a novel target has seen a focus on the glutamatergic system. ${ }^{14}$ The glutamate system is associated with the pathophysiology of mood disorders in various aspects. Autopsy studies have reported abnormal levels of glutamate in the cerebrospinal fluid, plasma, serum, and brain tissue of individuals with a mood disorder. ${ }^{15-18}$ Moreover, magnetic resonance spectroscopy imaging studies found abnormal levels and abnormal ratio of glutamate and gamma-aminobutyric acid (GABA) in some brain regions associated with mood. ${ }^{19,20}$ Glial cells play an important role in the regulation of glutamate signaling and can partially affect depression. ${ }^{21}$ Glial cells are extensively involved in glutamate metabolism and degradation, and loss of glial cells has been observed in the frontal cortex of patients with mood disorder. In addition, it has been discovered that chronic stress may damage astrocytes in the cerebral cortex and lead to development of depression. ${ }^{22}$ Reduced glial cell function due to chronic stress causes reduction in extracellular glutamate degradation and increased activation of NR2B-containing glutamatergic N-methyl-D-aspartate (NMDA) receptors, eventually leading to synaptic loss and activation of the apoptotic pathway.

Ketamine is an NMDA receptor antagonist prescribed as an anesthetic but also used off-label to treat chronic pain. After the study demonstrating that a subanesthetic dose of ketamine, when administered intravenously over 40 minutes, may have a rapid onset of antidepressant effect in patients with MDD, ketamine has been a focus of attention as a novel antidepressant with a novel target. ${ }^{23}$ Since then, evidence has been accumulating with many trials in patients with MDD. The rapid-acting antidepressant actions of ketamine have several complex molecular and cellular mechanisms, including NMDA receptor-mediated signaling, inhibition of extrasynaptic NMDA receptors, and ketamine metabolite actions, as well as the blockade of NMDA receptors in the synapse. In addition, intranasal ketamine for TRD has recently been approved by the FDA to ensure ease of administration and con- tinuous use to sustain antidepressant treatment. ${ }^{24}$

In this study, we reviewed the mechanism of action of ketamine as an antidepressant, its efficacy in treating MDD, and the safety and misuse potential of ketamine prescription, with a special focus on recent randomized control trials (RCTs).

\section{METHODS}

While it was our intent to systematically cover the existing literature about ketamine for treating MDD, we did not follow a Preferred Reporting Items for Systematic Reviews and MetaAnalyses (PRISMA) ${ }^{25}$ approach for a systematic review in the present report considering the anticipated publication bias in RCTs, especially concerning Phase-IV trials for non-intravenous ketamine for TRD. We rather opted for a narrative synthesis of the evidence promoting RCT appraisal whenever available. In contrast, in the absence of an RCT, we preferred to critically appraise the evidence by utilizing manual search, cross-reference augmentation, and consulting with the experts (as needed) in order to promote critical evaluation of the drug.

\section{THE MECHANISM OF ACTION OF KETAMINE AS AN ANTIDEPRESSANT}

\section{NMDA receptor blockade paradigm}

\section{Neurochemical antidepressant mechanism by blockade of NMDA receptor \\ NMDA receptors are glutamatergic and heterotetrameric li-} gand-gated ion channel receptors that are activated by concurrent binding of L-glutamate and glycine or D-serine to the GluN2 and GluN1 subunits or via flow of calcium ions when a depolarization repels the $\mathrm{Mg}^{2+}$ block from the ion channel pore in a voltage-dependent manner. In a forced swim test in mice, it was demonstrated that a non-competitive NMDA receptor antagonist and a competitive NMDA receptor antagonist have an antidepressant effect of reducing the duration of immobility in these mice. ${ }^{26}$ In the same experiment, long-term administration of antidepressants reduced the binding of a radioactive ligand to the NMDA receptors, which was believed to be an adaptive change of the receptor. Therefore, the researchers suggested that rapid-acting antidepressant actions were caused by direct blockade of NMDA receptors.

Ketamine blocks excitatory glutamate signaling and increases the overall activity of the prefrontal cortex ${ }^{27}$ by preferentially inhibiting NMDA receptors expressed in GABA neurons. ${ }^{28,29}$ This mechanism is supported by a preclinical study, which found that a non-competitive NMDA receptor antagonist, dizocilpine, inhibited the firing of GABA interneurons but increased the firing of pyramidal neurons. Ket- 
amine has a high affinity for the GluN2D subunit of the GluN2D-NMDA receptors that are highly expressed in the inhibitory interneurons of the forebrain. ${ }^{30}$ It is predicted that inhibition of NMDA receptors in GABAergic interneurons induces a general decrease in inhibition, which will then disinhibit pyramidal neurons and strengthen excitatory glutamate signaling in the medial prefrontal cortex. ${ }^{28}$ When a subanesthetic dose of ketamine is administered to mice, the extracellular glutamate concentration and glutamate cycling in the prefrontal cortex are increased. ${ }^{28,31}$

Ketamine may induce antidepressant actions through direct inhibition of extrasynaptic NMDA receptors. The presence of extrasynaptic NMDA receptors has been demonstrated through immunohistochemical and electrophysiological studies. ${ }^{32}$ GluN2B-containing extrasynaptic NMDA receptors located in dendrites near glial cells are not activated by transient synaptic glutamate release but are chronically activated by low levels of glutamate in the extracellular space. ${ }^{33,34}$ This tonic glutamate level is regulated by the glutamate transporter, EAAT2, which is expressed in glial cells. Ketamine inhibits glutamateinduced tonic actions through specific inhibition of extrasynaptic GluN2B-NMDA receptors, and this is presumed to induce excitation of pyramidal neurons. ${ }^{35}$ Activation of extrasyna ptic GluN2B-selective NMDA receptors occurs through the mTOR signaling pathway associated with inhibition of protein synthesis for homeostatic synaptic scaling, ${ }^{35-37}$ and, as such, blockade of the above receptors may induce antidepressant actions via disinhibition of protein synthesis and an mTOR-dependent mechanism. Although selective antagonism of GluN2B-containing NMDA receptors produces antidepressant actions, it is not as rapid-acting as the antidepressant effects of ketamine through other mechanisms. GluN2B-NMDA receptor antagonists, traxoprodil and MK-0657, elicited significant antidepressant actions approximately five days after their infusion. ${ }^{38,39}$

The lateral habenula is an epithalamic structure that plays a mediating role between the monoaminergic systems and the forebrain and midbrain. ${ }^{40}$ Activation of the lateral habenula neurons is associated with depression-like phenotypes in depressed animals and humans. In mice, depression and fatigue were associated with increased activity burst in the lateral habenula neurons. ${ }^{41}$ Direct application of ketamine to the lateral habenula neurons decreased the abnormally high levels of NMDA receptor-dependent firing bursts and induced immediate antidepressant effects. ${ }^{41}$ Further studies are needed to investigate whether other types of rapid-acting antidepressants share the same mechanism of action, whether these effects converge with other antidepressant actions of ketamine, and if the same results can be obtained in humans.

\section{The mechanism of enhancing synaptic plasticity by blockade of NMDA receptor}

The mechanism underlying the action of rapid-acting antidepressants comes from rapid changes in synaptic functions and neural plasticity. Ketamine increases the mTORC1 signaling through Akt and ERK activation and increases the number and function of synapses in the prefrontal cortex. ${ }^{35,42,43}$ This leads to increased synthesis of proteins required for the formation and maturation of synapses, which may be blocked by pre-infusion with a selective MTORC1 inhibitor rapamycin. ${ }^{35,42,44}$ The rapid activation of mTORC1 and dendritic mRNA translation of synaptic proteins by ketamine triggers continuous synapse formation and behavioral changes.

Ketamine-mediated mTORC1 activation, synapse formation, and antidepressant actions are determined by glutamate signaling and $\alpha$-amino-3-hydroxy-5-methyl-4-isoxazolepropionic acid (AMPA) receptor activation. Animal and clinical studies found that blockade of NMDA receptors on GABAergic interneurons increased glutamate signaling. ${ }^{28,29,45}$ In addition, activation of the AMPA receptor induced the release of BDNF in neurons and mTORC1 signaling through Akt and ERK signaling. ${ }^{46,47}$ In contrast to ketamine's activity-dependent BDNF release, monoamine antidepressants do not induce the release of BDNF but increase BDNF expression through complex intracellular signaling cascades. ${ }^{48}$ This process is relatively slower than the antidepressant action of ketamine. ${ }^{11}$

The rapid induction of mTORC1 signaling and synaptogenesis recovers the synaptic loss between neurons in patients with depression and restores the ability to adequately control emotions in the prefrontal lobe and amygdala. This has been demonstrated by a chronic stress-depression rat model exposed to stress for several weeks. ${ }^{49}$ The rats in this study exhibited prefrontal neuron atrophy and anhedonia, which are characteristic of depression; however, a single dose of ketamine rapidly improved the aforementioned structural deficit and behavioral problems. This has also been demonstrated with brain imaging studies in animals and in clinical studies showing that ketamine increased the connectivity of the prefrontal lobe with the limbic system in species with depression. .0,51 $^{2}$

Independent synaptic vesicle glutamate release via independent fusion of synaptic vesicles at presynaptic terminals induces miniature excitatory postsynaptic currents (mEP$\mathrm{SCs}$ ), which regulate synaptic strength and protein synthesis. ${ }^{52-54}$ mEPSCs inhibit protein synthesis while blocking NMDA receptor-mediated neurotransmission, and the resulting selective depletion of vesicles led to synaptic strengthening in the hippocampus. ${ }^{54}$ Ketamine blocked resting NMDA receptor-mediated neurotransmission, eliciting disinhibition of protein synthesis leading to the induction of synaptic strengthening in the CA1 regions of the hippocam- 
pus and improving depression..$^{54,55}$ The inhibition of NMDA receptor-mediated neurotransmission by ketamine occurs in the presence of physiological concentrations of $\mathrm{Mg}^{2+}$ and leads to a rapid-acting antidepressant action. ${ }^{56}$ This is different from memantine, which is reduced in NMDA receptor antagonism-mediated mEPSCs at the physiological level of $\mathrm{Mg}^{2+}$ and lacks a rapid-acting antidepressant action. ${ }^{56}$

\section{NMDA receptor blockade-independent paradigm}

\section{Evidence of NMDA receptor inhibition-independent mechanism of action}

After the discovery of the ability of ketamine to produce rapid-acting and long-lasting antidepressant actions, clinical trials were conducted to investigate the antidepressant potential of other NMDA receptor antagonists with similar NMDA inhibition as ketamine. However, clinical trials showed that these alternative NMDA receptor antagonists lack the rapidacting and long-lasting antidepressant actions of ketamine. ${ }^{57}$ In particular, memantine, a prescription drug for the treatment of moderate to severe dementia related to Alzheimer's disease, repeatedly failed to produce antidepressant actions in patients with MDD. ${ }^{58,59}$ In addition, a non-selective NMDA receptor antagonist, lanicemine, did not reproduce the longlasting antidepressant effect of ketamine in MDD patients, ${ }^{60}$ and in the follow-up clinical trial, no significant difference was found between adjunctive lanicemine treatment and placebo treatment. ${ }^{61}$ This suggests an antidepressant mechanism of ketamine that is independent of NMDA receptor inhibition.

\section{Antidepressant action of metabolites of ketamine}

(2S,6S;2R,6R)-hydroxynorketamine (HNK) is a key metabolite of ketamine found in the plasma and brain in humans. ${ }^{62}$ (2S,6S;2R,6R)-HNK has been considered inactive since it does not affect anesthetic action. An animal study found evidence that the metabolism of ketamine to $(2 \mathrm{~S}, 6 \mathrm{~S} ; 2 \mathrm{R}, 6 \mathrm{R})$ HNK is needed for its antidepressant actions. ${ }^{63}$ Chemical alteration of ketamine by deuteration at the C6 position did not change the binding affinity of ketamine for NMDA receptors but sharply reduced its metabolism to (2S,6S;2R,6R)-HNK. This alteration blocked the antidepressant actions of ketamine in mice and demonstrated that $(2 \mathrm{~S}, 6 \mathrm{~S} ; 2 \mathrm{R}, 6 \mathrm{R})$-HNK is required for ketamine antidepressant responses. However, in a recent contradictory study, mice were pretreated with cytochrome p450 inhibitors and did not show (2R,6R)-HNK after administration of (R)-ketamine induced an antidepressant action, indicating that $(2 \mathrm{R}, 6 \mathrm{R})-\mathrm{HNK}$ is not essential for ketamine's antidepressant action. ${ }^{64}$ Therefore, it is still difficult to conclude that ketamine metabolites have antidepressant action, and human data on it are also needed.

\section{EFFICACY OF KETAMINE IN MDD}

\section{Evidence in support of intravenous injection of ketamine for MDD}

In 2000, Berman et al. ${ }^{23}$ investigated ketamine as a potential antidepressant for the first time. Using a small number of subjects $(n=7)$, they found that mood symptoms rapidly improved within four hours in response to ketamine $(0.5 \mathrm{mg} / \mathrm{kg}$ infusion over 40 minutes) infusion, whereas no response was found with placebo (normal saline) infusion. Ketamine infusion reduced the Hamilton Depression Rating Scale score, a measure of depression severity, by an average of 13 points. This result was reproduced in a subsequent crossover study. ${ }^{65} \mathrm{~Pa}-$ tients who had previously failed at least two antidepressant clinical treatments were treated with ketamine or placebo and then crossed over one week later. Rapid antidepressant effects were observed within 2 hours post-infusion in patients treated with ketamine when compared with placebo-treated individuals.

In a placebo-controlled study, it is difficult for a non-active placebo such as normal saline to produce a dissociative effect that peaks at 15 to 30 minutes after the start of infusion. In order to enhance the effect of blinding, some researchers used midazolam, a short-acting benzodiazepine, in an active control group; $0.045 \mathrm{mg} / \mathrm{kg}$ midazolam produces perceptual and cognitive changes with infusion times similar to that of ketamine and may be intravenously administered. However, it must be taken into consideration that benzodiazepines may also have antidepressant effects. ${ }^{66}$ Murrough et al. ${ }^{67}$ were the first to conduct a parallel, double-blind, randomized study with ketamine and midazolam for treating TRD. Patients with TRD not undergoing pharmacotherapy were randomly assigned to receive a ketamine or midazolam infusion (2:1 ratio). In the ketamine group, 30 out of 47 patients showed a response within 24 hours of infusion (50\% or greater reduction in symptoms), whereas 7 out of 25 patients in the midazolam group showed a response. The antidepressant effects of ketamine are superior to those of midazolam; however, the effect size for the antidepressant effect of ketamine somewhat decreases when compared to that in studies that used saline solution as a placebo.

Two studies of the same design found antidepressant effects of ketamine on bipolar depression in patients with treatmentresistant bipolar depression. ${ }^{68,69}$ The subjects were maintained on lithium or valproate prior to the study protocol. Using a crossover design with a one-week wash-out period, it was found that ketamine produces a rapid antidepressant effect in bipolar depression. However, the effect started to disappear within one week of infusion in most of the patients.

Sos et al. ${ }^{70}$ randomly assigned 30 hospitalized patients to first receive ketamine or a placebo, and then they were crossed over 
after one week. In this protocol, the ketamine dose was different. Subjects received $0.27 \mathrm{mg} / \mathrm{kg}$ over 10 minutes, followed by an additional $0.27 \mathrm{mg} / \mathrm{kg}$ for 20 minutes $(0.54 \mathrm{mg} / \mathrm{kg}$ administered over 30 minutes). Ketamine produced a stronger and superior effect than placebo, as 10 out of 27 patients had a response after ketamine infusion, while only 1 out of 19 patients had a response after placebo infusion.

Hu et al. ${ }^{71}$ investigated the efficacy of single-dose ketamine augmentation of standard antidepressants. In this parallel study, 30 patients with severe major depressive disorder were randomly assigned to ketamine $[0.5 \mathrm{mg} / \mathrm{kg}$ intravenous (IV) infusion over 40 minutes] or a placebo group. All patients were started on escitalopram on the same day of ketamine infusion. At week 4 of treatment, the response and remission rates of the ketamine group were greater when compared to those of the placebo group. The time until the response of the ketamine group was shorter than that of the placebo group.

Based on the fact that patients with chronic pain sometimes receive prolonged ketamine infusion, ${ }^{72}$ Lenze et al. ${ }^{73}$ applied a similar protocol in their study of depression. Twenty participants were randomly assigned to two groups that received a continuous infusion of $0.6 \mathrm{mg} / \mathrm{kg} / \mathrm{h}$ ketamine for 96 hours and a standard ketamine infusion $(0.5 \mathrm{mg} / \mathrm{kg}$ over $40 \mathrm{~min}$ utes). In this protocol, both groups received clonidine in order to prevent dissociative and psychotomimetic effects and minimize the increase in blood pressure. Bipolar symptoms were measured using the Brief Psychiatric Rating Scale, and although the score peaked on day 3 in the 96-ketamine infusion group, the changes of these symptoms were similar to those obtained with the standard protocol. Rapid and sustained improvement in depressive symptoms was found in both protocol groups.

A meta-analysis of the aforementioned seven double-blind RCTs employing an IV infusion and one RCT employing intranasal (IN) ketamine in the treatment of major depressive episodes in patients with bipolar disorder and MDD showed that a single administration of ketamine may have rapid antidepressant effects. ${ }^{74}$

All the previous studies, to date, were RCTs with relatively small number of subjects. A large-scale RCT comprising a large number of subjects is being conducted and the results are currently being reported (Table 1). In order to establish evidence on the optimal ketamine dose, an RCT compared $0.1(n=18), 0.2(n=20), 0.5(n=22)$, and $1.0 \mathrm{mg}(\mathrm{n}=20)$ ketamine with an active placebo (midazolam $0.45 \mathrm{mg} / \mathrm{kg}, \mathrm{n}=19$ ) in TRD. This comparison showed that, although the effect of a low dose $(0.1$ and $0.2 \mathrm{mg} / \mathrm{kg}$ ) ketamine was ambiguous, a ketamine dose of $0.5 \mathrm{mg} / \mathrm{kg}$ or greater was clearly more efficacious than the active placebo. ${ }^{75}$ Other studies in which repeated infusions following a single dose infusion were employed and the analyses of the efficacy of this infusion regimen at different times are discussed in the following section.

A single dose IV ketamine administration produced consistent antidepressant effects only for a maximum of seven days; therefore, there is a need to investigate whether repeated ketamine infusion produces a better response rate and better maintenance of antidepressant effects. In the first open-label study that investigated the effect of six IV ketamine infusions over two weeks, $70.8 \%$ of patients with TRD showed a response, and the median relapse time was 18 days. Treatment results were strongly predicted by the response at four hours after the first infusion.

In contrast, a study, in which 28 participants with unipolar and bipolar TRD received IV ketamine infusion three or six times a week over three weeks, showed that $29 \%$ of the patients responded to the ketamine treatment. ${ }^{76}$ In this study, $11 \%$ of the patients showed a response within six hours after a single dose infusion, and in all responders, a response was seen before the third infusion. Further, following the last infusion, the treatment effect lasted for 25 to 168 days.

However, in an RCT of 26 patients with severe TRD and chronic suicidal ideation who received six IV ketamine augmentation doses or placebo for over three weeks, the ketamine infusion group did not show a higher treatment effect when compared to the placebo infusion group. The authors suggested that a standard $0.5 \mathrm{mg} / \mathrm{kg}$ dose or administration period may be insufficient for patients with severe TRD and chronic suicidal ideation. ${ }^{77}$

According to the first multicenter RCT $(n=67)$ in which a twice-weekly or thrice-weekly IV ketamine $(0.5 \mathrm{mg} / \mathrm{kg}$ administered over 40 minutes for four weeks) group was compared with a twice-weekly or thrice-weekly IV placebo group, both ketamine doses were similarly effective in reducing depressive symptoms in contrast to the placebo. ${ }^{78}$ In this study, all responders also responded before the third administration. The adverse effect profiles were similar between the twiceweekly and thrice-weekly groups.

A recent repeated ketamine infusion study evaluated the cumulative and sustained therapeutic effects of repeated ketamine infusion after confirming the efficacy of a single dose infusion. Phillips et al. ${ }^{79}$ found that, in 46 patients with TRD, a single IV infusion of ketamine produced a greater reduction in depressive symptoms when compared to that with the active control, midazolam. The patients then received six ketamine infusions administered thrice weekly over two weeks, and $59 \%$ of the patients had a $50 \%$ or greater decrease in their Montgomery-Åsberg Depression Rating Scale score (MADRS). These patients then received a maintenance treatment once a week for four weeks, and their MADRS score was maintained without relapse. 


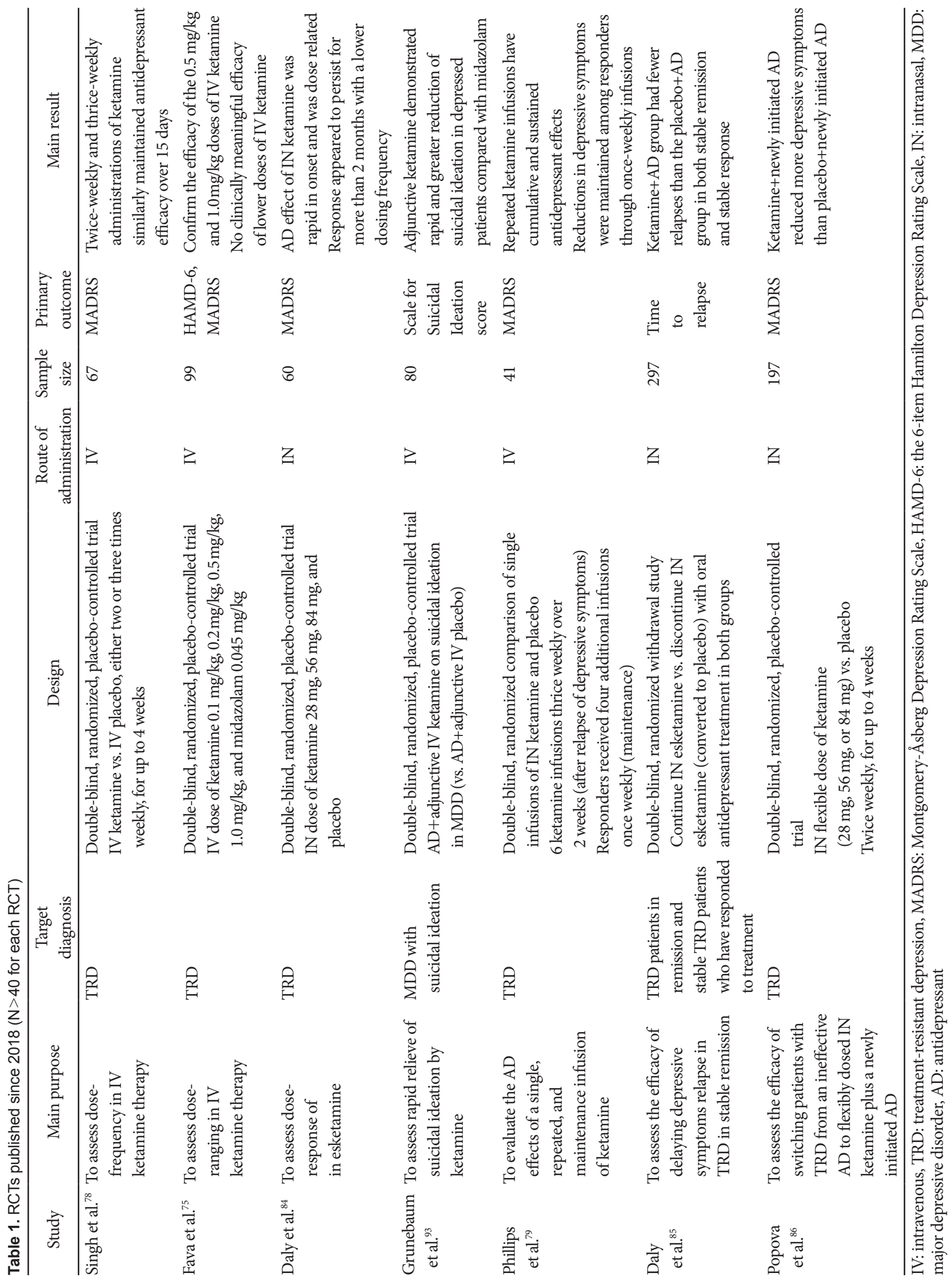




\section{Evidence in support of intranasal injection of ketamine for MDD}

Ketamine has been administered intranasally as an analgesic, and this form of administration is known to be less invasive and well-tolerated than IV infusion. ${ }^{80,81}$ Intranasal ketamine has been shown to be effective within minutes, which has been hypothetically suggested due to blockage of the NMDA receptor circuits that generate the emotional representations of pain. ${ }^{82}$ Lapidus et al. ${ }^{83}$ firstly investigated whether IN ketamine administration produces an antidepressant effect in patients with MDD. Eighteen patients with TRD were randomized to receive $50 \mathrm{mg}$ of IN racemic ketamine or placebo before the end of a one-week drug-free period. At 24 hours following administration, 8 out of 18 patients showed a response to ketamine treatment and only 1 out of 18 showed a response to placebo treatment.

In a recently published study, participants were randomized into a placebo and s-ketamine 28,56 , or $84 \mathrm{mg}$ twice weekly groups at a 3:1:1:1 ratio, and patients in the placebo group who had moderate to severe symptoms were randomly assigned again to the three ketamine groups. ${ }^{84}$ The participants then received infusion twice weekly for two weeks, followed by an open-label treatment with administration once weekly for three weeks followed by a maintenance infusion once every two weeks for up to 10 weeks. In this study, all the ketamine groups demonstrated superior antidepressant effects than the placebo group. In addition, it was concluded that the antidepressant effect was sustained even with reduced dosing frequency.

A placebo-controlled study designed to investigate the maintenance effect of ketamine treatment was recently reported. In this RCT, patients with MDD ( $\mathrm{n}=121)$ who achieved remission or stable response $(50 \%$ or greater reduction in MADRS score for two weeks or longer) after IN s-ketamine treatment, received additional administration of 56 or $84 \mathrm{mg}$ esketamine as an adjunctive therapy plus an oral antidepressant during the maintenance phase. Relapse was significantly delayed in the ketamine group. ${ }^{85}$

In a recent study, IN ketamine flexible doses $(28,56$, or 84 $\mathrm{mg}$ ) twice weekly for 4 weeks with oral antidepressants significantly reduced the depressive symptoms in TRD patients. ${ }^{86}$ In contrast, an abstract of an unpublished study using the same design showed that IN ketamine plus oral antidepressant did not significantly reduce the depressive symptoms in TRD patients $>65$ years of age in all the study regions except in the United States. ${ }^{87}$

\section{THE RAPID-ACTING ANTI-SUICIDAL EFFECT OF KETAMINE}

Suicidal ideation is the most serious symptom of depression and is one of the leading causes of death. ${ }^{88}$ Suicidal ideation has been suggested as a symptom caused by cognitive dysfunction, especially associated with dysregulation of glutaminergic neurotransmission in the prefrontal cortex in patients with MDD with suicidal ideation. The antidepressant effects of ketamine through the glutamate pathway has been reported to exert anti-suicidal effect by preclinical studies. ${ }^{89}$ Although most pharmacological studies on depression exclude individuals with imminent risk of suicide, several ketamine studies have included patients with a moderate level of suicidal ideation. In many case series and open-label studies, ketamine infusion consistently reduced suicidal ideation. ${ }^{90} \mathrm{~A}$ review of an RCT on the effects of ketamine on suicidality showed that a single infusion of ketamine reduced suicidal ideation in patients with TRD. ${ }^{91}$ A study involving suicidal psychiatric inpatients with various mood and anxiety spectrum disorders $(\mathrm{n}=24)$ showed that, when compared with midazolam, IV ketamine produced a significant reduction in suicidal ideation at post-infusion day 2 , although the significance was lost at day $7 .^{92}$ In an RCT of 80 MDD patients with suicidal ideation, suicidal ideation was significantly reduced in the single adjunctive subanesthetic IV ketamine infusion group $(n=40)$ when compared with the midazolam control group $(n=40)$ and the observed decrease in suicidal ideation was maintained following infusion. ${ }^{93}$ In an RCT to determine the effect of IN esketamine on depressive symptoms and suicidal thoughts in MDD patients at risk for suicide, repeated infusion of $84 \mathrm{mg}$ of IN esketamine (twice weekly through day 25 , once weekly through day 52 , and once every other week through day 81 ) significantly decreased the MADRS total score and MADRS suicidal ideation item scores when compared with IN-placebo infusion. ${ }^{94}$ In a recent RCT, ketamine administration in MDD patients reduced the functional connectivity of the left dorsolateral prefrontal cortex and the left dorsal anterior cingulate cortex. ${ }^{95}$ This seems to correlate with the antidepressant and anti-suicidal effects of ketamine infusion. Rapid improvement of suicidal ideation suggests that ketamine may be administered first in a clinical setting when urgent treatment is needed, as in patients with suicidal ideation or behavior.

\section{SAFETY AND ABUSE ISSUES}

It has been demonstrated that healthy volunteers experience psychotomimetic symptoms, perceptual impairment, dissociative symptoms, or reduced cognitive function during ketamine infusion using the standard protocol $(0.5 \mathrm{mg} / \mathrm{kg}$ over $40 \mathrm{~min}$ utes or longer intravenously). ${ }^{96,97}$ These side effects were resolved within approximately 40 to 80 minutes of infusion completion. Patients with a mood disorder have shown, with repeated dosing, some resistance to the acute dissociative and 
psychotic symptoms induced by ketamine. Moreover, subjects with TRD who received low dose IV ketamine showed improvement in cognitive function. ${ }^{98}$

A meta-analysis of depression reported that a single use of ketamine for the treatment of depression can cause adverse symptoms including dizziness, blurred vision, headache, nausea, vomiting, and dry mouth as other mild side effects, but these were generally not serious and resolved after dose administration. ${ }^{99}$ It has also been proposed that, although the side effect of blood pressure elevation during and shortly after a 40-minute ketamine infusion is transient, careful monitoring is required for patients with a history of cardiovascular disease as transient blood pressure elevations may be problematic in such patients. ${ }^{100} \mathrm{~A}$ recent systemic review reported that it is still difficult to conclude that repeated dosing of ketamine has a cumulative effect and long-term risk because of insufficient data. ${ }^{101}$

Lamotrigine, and other glutamate release-inhibiting drugs may reduce hyper-glutamatergic consequences presented as perceptual abnormalities. ${ }^{102}$ Thus, glutamatergic inhibition of lamotrigine could prevent hyperglutamatergic activation due to ketamine abuse, with potential benefit identified in some case reports. ${ }^{103}$ This property of lamotrigine may cause downregulation of ketamine's antidepressant action.

The interaction of ketamine and opioid receptors, including $\mathrm{mu}$, delta, and kappa, have been considered to have an antinociceptive role in acute and chronic pain. Interestingly, in human studies, pretreatment with naltrexone, an opioid receptor antagonist, decreased the antidepressant action of ketamine but did not alter its dissociative effects. ${ }^{104}$ This suggests that the opioid system may play an important role in the antidepressant action of ketamine, but may not be involved in the development of adverse effects (dissociative symptoms).

Whether repeated use of ketamine can result in prolonged cognitive and perceptual changes or psychosis-like symptoms is an important issue. This is especially important because a method for maintaining the antidepressant effects of ketamine without repeated ketamine exposure is unclear. The most useful evidence for the long-term effects of ketamine comes from a study involving ketamine abusers. Although it is evident that reduced cognitive function, thought disorder, or neuropsychiatric abnormality, including depression, may arise from ketamine abuse, this is dose-dependent and limited to frequent users who use ketamine almost every day. ${ }^{105}$

Because ketamine has been used as a recreational drug, there is a potential for patients to abuse its use or to develop a use disorder. ${ }^{106}$ Ketamine abuse is a common global problem, and, although the prevalence of its abuse in Korea has not been studied, $1.7 \%$ of adolescents in the United States abuse it one or more times a year. ${ }^{107}$ Ketamine abuse is also common in the Asian regions of Hong Kong and Taiwan, with a prevalence of $1.1 \%$ to $1.8 \%{ }^{108}$ However, many aspects of ketamine abuse are not yet well known, including risk factors that increase ketamine abuse. A long-term study is needed to investigate whether ketamine use in patients with depression leads to its abuse.

\section{PREDICTOR OF RESPONSE TO KETAMINE}

Several clinical studies have demonstrated the efficacy of ketamine infusion in resolving symptoms in patients with MDD. It is not yet well-known which patients will have favorable outcomes after ketamine treatment. An evaluation of ketamine responders vs. non-responders after a single infusion showed no difference in patients with different demographic and clinical characteristics. ${ }^{98}$ A study by Murrough et al. ${ }^{109}$ found that, in a neuropsychology test, slower processing speed at baseline was a predictor of larger improvements in depression at 24 hours following ketamine treatment. This finding is in contrast with that of a previous study that predicted that a slow processing speed is associated with poor antidepressant response. ${ }^{110}$ Monteggia et al. ${ }^{111}$ suggested that high body mass index, family history of alcohol use disorder, and anxiety were clinical predictors of ketamine treatment. An earlier study found that patients with anxious depression responded better to ketamine treatment. ${ }^{112}$ However, a recent study found no difference in the response to ketamine infusion between patients with anxious and non-anxious depression. ${ }^{113}$ More research on the predictors of ketamine treatment response in patients with MDD is still needed.

\section{CONCLUSIONS}

Mounting evidence supports the acute therapeutic efficacy of ketamine for MDD; however, several issues need clarification, if ketamine is to be used as an antidepressant. Clinical trials are being conducted to optimize the efficacy of ketamine, indicating the lack of standard guidelines, outside of the research environment. Recently, large-scale RCTs have outlined the administration protocol for the use of ketamine as an antidepressant. IN and IV ketamine administration are effective for MDD in subanesthetic doses, with an ascending dose-response relationship. However, low doses (below $0.5 \mathrm{mg} / \mathrm{kg}$ ) of IV ketamine cannot ensure an antidepressant effect. In terms of treatment frequency, two to three repeated ketamine administrations per week may be required to maintain antidepressant efficacy. Moreover, weekly maintenance doses could be used for maintaining remission or a significant response. The minimal adverse effects of ketamine at subanesthetic doses observed dur- 
ing the trials were encouraging in terms of its safety.

Little is known about the safety of long-term exposure to subanesthetic doses of ketamine when prescribed as an antidepressant; it is presumed that some data will become available from a small observational study on ketamine abusers, which is currently underway. Considering that an increasing number of medical institutions have been using ketamine, off-label, for the treatment of psychological disorders, ${ }^{114}$ studies on evidence-based treatment methods and a better understanding of the long-term risks of ketamine are indispensable.

We emphasize that IN ketamine will be in widespread use in the future because IN ketamine is less invasive and easier to use than IV ketamine. Recently, a large-scale clinical trial of the effects of IN ketamine on MDD successfully ended, with the efficacy and safety of IN ketamine considerably clarified. Subsequently, IN ketamine (trade name: Spravato) was approved by the FDA as an adjunct to oral antidepressants for TRD. ${ }^{24,115}$ Clearly, IN formulations of ketamine are restricted for use only under medical supervision at medical institutions.

In conclusion, important studies support the efficacy of ketamine as rapid-acting pharmacotherapy for patients with MDD. Clinicians should remember that information related to the optimum dose and the long-term effects of ketamine treatment are still being updated. As more evidence becomes available in the future, ketamine is expected to have important clinical applications in the rapid resolution of serious depressive symptoms, including suicidal ideation, and as an effective treatment for TRD.

\section{Acknowledgments}

None.

\section{Conflicts of Interest}

The authors have no potential conflicts of interest to disclose.

\section{Author Contributions}

Conceptualization: Yong-Ku Kim. Investigation: Cheolmin Shin. Methodology: Cheolmin Shin, Yong-Ku Kim. Project administration: Yong-Ku Kim. Supervision: Yong-Ku Kim. Writing_original draft: Cheolmin Shin. Writingreview \& editing: Cheolmin Shin and Yong-Ku Kim.

\section{ORCID iDs}

$\begin{array}{ll}\text { Cheolmin Shin } & \text { https://orcid.org/0000-0002-8232-2921 } \\ \text { Yong-Ku Kim } & \text { https://orcid.org/0000-0001-5694-7840 }\end{array}$

\section{REFERENCES}

1. Ferrari AJ, Somerville AJ, Baxter AJ, Norman R, Patten SB, Vos T, et al. Global variation in the prevalence and incidence of major depressive disorder: a systematic review of the epidemiological literature. Psychol Med 2013;43:471-481.

2. Correll CU, Solmi M, Veronese N, Bortolato B, Rosson S, Santonastaso $\mathrm{P}$, et al. Prevalence, incidence and mortality from cardiovascular disease in patients with pooled and specific severe mental illness: a large-scale meta-analysis of 3,211,768 patients and 113,383,368 controls. World Psychiatry 2017;16:163-180.
3. Rush AJ, Trivedi MH, Wisniewski SR, Nierenberg AA, Stewart JW, Warden D, et al. Acute and longer-term outcomes in depressed outpatients requiring one or several treatment steps: a $\mathrm{STAR}^{\star} \mathrm{D}$ report. Am J Psychiatry 2006;163:1905-1917.

4. Katz MM, Tekell JL, Bowden CL, Brannan S, Houston JP, Berman N, et al. Onset and early behavioral effects of pharmacologically different antidepressants and placebo in depression. Neuropsychopharmacology 2004;29:566-579.

5. Machado-Vieira R, Salvadore G, Luckenbaugh DA, Manji HK, Zarate CA Jr. Rapid onset of antidepressant action: a new paradigm in the research and treatment of major depressive disorder. J Clin Psychiatry 2008;69:946-958.

6. Fava M, Davidson KG. Definition and epidemiology of treatment-resistant depression. Psychiatr Clin North Am 1996;19:179-200.

7. Frazer A, Benmansour S. Delayed pharmacological effects of antidepressants. Mol Psychiatry 2002; 7(Suppl 1): S23-S28.

8. Posternak MA, Zimmerman M. Is there a delay in the antidepressant effect? A meta-analysis. J Clin Psychiatry 2005; 66: 148-158.

9. Insel TR, Wang PS. The STAR ${ }^{\star} \mathrm{D}$ trial: revealing the need for better treatments. Psychiatr Serv 2009;60:1466-1467.

10. Gelenberg AJ, Chesen CL. How fast are antidepressants? J Clin Psychiatry 2000;61:712-721.

11. Harmer CJ, Duman RS, Cowen PJ. How do antidepressants work? New perspectives for refining future treatment approaches. Lancet Psychiatry 2017;4:409-418.

12. Insel TR, Scolnick EM. Cure therapeutics and strategic prevention: raising the bar for mental health research. Mol Psychiatry 2006;11: 11-17.

13. Dragioti E, Solmi M, Favaro A, Fusar-Poli P, Dazzan P, Thompson T, et al. Association of antidepressant use with adverse health outcomes: a systematic umbrella review. JAMA Psychiatry 2019 [Epub ahead of print].

14. Tomasetti C, Montemitro C, Fiengo ALC, Santone C, Orsolini L, Valchera A, et al. Novel pathways in the treatment of major depression: focus on the glutamatergic system. Curr Pharm Des 2019;25: 381-387.

15. Altamura CA, Mauri MC, Ferrara A, Moro AR, D’Andrea G, Zamberlan F. Plasma and platelet excitatory amino acids in psychiatric disorders. Am J Psychiatry 1993;150:1731-1733.

16. Frye MA, Watzl J, Banakar S, O’Neill J, Mintz J, Davanzo P, et al. Increased anterior cingulate/medial prefrontal cortical glutamate and creatine in bipolar depression. Neuropsychopharmacology 2007;32: 2490-2499.

17. Mauri MC, Ferrara A, Boscati L, Bravin S, Zamberlan F, Alecci M, et al. Plasma and platelet amino acid concentrations in patients affected by major depression and under fluvoxamine treatment. Neuropsychobiology 1998;37:124-129.

18. Mitani H, Shirayama Y, Yamada T, Maeda K, Ashby CR Jr, Kawahara R. Correlation between plasma levels of glutamate, alanine and serine with severity of depression. Prog Neuropsychopharmacol Biol Psychiatry 2006;30:1155-1158.

19. Hasler G, van der Veen JW, Tumonis T, Meyers N, Shen J, Drevets WC. Reduced prefrontal glutamate/glutamine and gamma-aminobutyric acid levels in major depression determined using proton magnetic resonance spectroscopy. Arch Gen Psychiatry 2007;64: 193-200.

20. Abdallah CG, Niciu MJ, Fenton LR, Fasula MK, Jiang L, Black A, et al. Decreased occipital cortical glutamate levels in response to successful cognitive-behavioral therapy and pharmacotherapy for major depressive disorder. Psychother Psychosom 2014;83:298-307.

21. Sanacora G, Banasr M. From pathophysiology to novel antidepressant drugs: glial contributions to the pathology and treatment of mood disorders. Biol Psychiatry 2013;73:1172-1179.

22. Banasr M, Chowdhury GM, Terwilliger R, Newton SS, Duman RS, Behar KL, et al. Glial pathology in an animal model of depression: 
reversal of stress-induced cellular, metabolic and behavioral deficits by the glutamate-modulating drug riluzole. Mol Psychiatry 2010;15: 501-511.

23. Berman RM, Cappiello A, Anand A, Oren DA, Heninger GR, Charney DS, et al. Antidepressant effects of ketamine in depressed patients. Biol Psychiatry 2000;47:351-354.

24. FDA approves new nasal spray medication for treatment-resistant depression; available only at a certified doctor's office or clinic. Available at: https://www.fda.gov/news-events/press-announcements/fdaapproves-new-nasal-spray-medication-treatment-resistant-depression-available-only-certified. Accessed March 05, 2019.

25. Moher D, Shamseer L, Clarke M, Ghersi D, Liberati A, Petticrew M, et al. Preferred reporting items for systematic review and meta-analysis protocols (PRISMA-P) 2015 statement. Syst Rev 2015;4:1.

26. Trullas R, Skolnick P. Functional antagonists at the NMDA receptor complex exhibit antidepressant actions. Eur J Pharmacol 1990;185:1-10.

27. Breier A, Malhotra AK, Pinals DA, Weisenfeld NI, Pickar D. Association of ketamine-induced psychosis with focal activation of the prefrontal cortex in healthy volunteers. Am J Psychiatry 1997;154:805-811.

28. Moghaddam B, Adams B, Verma A, Daly D. Activation of glutamatergic neurotransmission by ketamine: a novel step in the pathway from NMDA receptor blockade to dopaminergic and cognitive disruptions associated with the prefrontal cortex. J Neurosci 1997;17:2921-2927.

29. Homayoun H, Moghaddam B. NMDA receptor hypofunction produces opposite effects on prefrontal cortex interneurons and pyramidal neurons. J Neurosci 2007;27:11496-11500.

30. Khlestova E, Johnson JW, Krystal JH, Lisman J. The Role of GluN2CContaining NMDA Receptors in Ketamine's Psychotogenic Action and in Schizophrenia Models. J Neurosci 2016;36:11151-11157.

31. Chowdhury GM, Zhang J, Thomas M, Banasr M, Ma X, Pittman B, et al. Transiently increased glutamate cycling in rat PFC is associated with rapid onset of antidepressant-like effects. Mol Psychiatry 2017; 22:120-126.

32. Hardingham GE, Bading H. Synaptic versus extrasynaptic NMDA receptor signalling: implications for neurodegenerative disorders. Nat Rev Neurosci 2010;11:682-696.

33. Rothstein JD, Dykes-Hoberg M, Pardo CA, Bristol LA, Jin L, Kuncl RW, et al. Knockout of glutamate transporters reveals a major role for astroglial transport in excitotoxicity and clearance of glutamate. Neuron 1996;16:675-686

34. Guo H, Lai L, Butchbach ME, Stockinger MP, Shan X, Bishop GA, et al. Increased expression of the glial glutamate transporter EAAT2 modulates excitotoxicity and delays the onset but not the outcome of ALS in mice. Hum Mol Genet 2003;12:2519-2532.

35. Miller OH, Yang L, Wang CC, Hargroder EA, Zhang Y, Delpire E, et al. GluN2B-containing NMDA receptors regulate depression-like behavior and are critical for the rapid antidepressant actions of ketamine. Elife 2014;3:e03581.

36. Gray JA, Shi Y, Usui H, During MJ, Sakimura K, Nicoll RA. Distinct modes of AMPA receptor suppression at developing synapses by GluN2A and GluN2B: single-cell NMDA receptor subunit deletion in vivo. Neuron 2011;71:1085-1101.

37. Wang CC, Held RG, Hall BJ. SynGAP regulates protein synthesis and homeostatic synaptic plasticity in developing cortical networks. PLoS One 2013;8:e83941.

38. Preskorn SH, Baker B, Kolluri S, Menniti FS, Krams M, Landen JW. An innovative design to establish proof of concept of the antidepressant effects of the NR2B subunit selective N-methyl-D-aspartate antagonist, CP-101,606, in patients with treatment-refractory major depressive disorder. J Clin Psychopharmacol 2008;28:631-637.

39. Ibrahim L, Diaz Granados N, Jolkovsky L, Brutsche N, Luckenbaugh DA, Herring WJ, et al. A Randomized, placebo-controlled, crossover pilot trial of the oral selective NR2B antagonist MK-0657 in patients with treatment-resistant major depressive disorder. J Clin Psychopharmacol 2012;32:551-557.
40. Boulos LJ, Darcq E, Kieffer BL. Translating the Habenula-From Rodents to Humans. Biol Psychiatry 2017;81:296-305.

41. Yang Y, Cui Y, Sang K, Dong Y, Ni Z, Ma S, et al. Ketamine blocks bursting in the lateral habenula to rapidly relieve depression. Nature 2018;554:317-322.

42. Li N, Lee B, Liu RJ, Banasr M, Dwyer JM, Iwata M, et al. mTOR-dependent synapse formation underlies the rapid antidepressant effects of NMDA antagonists. Science 2010;329:959-964.

43. Zhou W, Wang N, Yang C, Li XM, Zhou ZQ, Yang JJ. Ketamine-induced antidepressant effects are associated with AMPA receptorsmediated upregulation of mTOR and BDNF in rat hippocampus and prefrontal cortex. Eur Psychiatry 2014;29:419-423.

44. Liu RJ, Ota KT, Dutheil S, Duman RS, Aghajanian GK. Ketamine strengthens CRF-activated amygdala inputs to basal dendrites in mPFC layer V Pyramidal cells in the prelimbic but not infralimbic subregion, a key suppressor of stress responses. Neuropsychopharmacology 2015;40:2066-2075.

45. Stone JM, Dietrich C, Edden R, Mehta MA, De Simoni S, Reed LJ, et al. Ketamine effects on brain GABA and glutamate levels with $1 \mathrm{H}-$ MRS: relationship to ketamine-induced psychopathology. Mol Psychiatry 2012;17:664-665.

46. Jourdi H, Hsu YT, Zhou M, Qin Q, Bi X, Baudry M. Positive AMPA receptor modulation rapidly stimulates $\mathrm{BDNF}$ release and increases dendritic mRNA translation. J Neurosci 2009;29:8688-8697.

47. Takei N, Inamura N, Kawamura M, Namba H, Hara K, Yonezawa K, et al. Brain-derived neurotrophic factor induces mammalian target of rapamycin-dependent local activation of translation machinery and protein synthesis in neuronal dendrites. J Neurosci 2004;24: 9760-9769.

48. Bjorkholm C, Monteggia LM. BDNF-a key transducer of antidepressant effects. Neuropharmacology 2016;102:72-79.

49. Li N, Liu RJ, Dwyer JM, Banasr M, Lee B, Son H, et al. Glutamate Nmethyl-D-aspartate receptor antagonists rapidly reverse behavioral and synaptic deficits caused by chronic stress exposure. Biol Psychiatry 2011;69:754-761.

50. Gass N, Schwarz AJ, Sartorius A, Schenker E, Risterucci C, Spedding $\mathrm{M}$, et al. Sub-anesthetic ketamine modulates intrinsic BOLD connectivity within the hippocampal-prefrontal circuit in the rat. Neuropsychopharmacology 2014;39:895-906.

51. Murrough JW, Collins KA, Fields J, DeWilde KE, Phillips ML, Mathew SJ, et al. Regulation of neural responses to emotion perception by ketamine in individuals with treatment-resistant major depressive disorder. Transl Psychiatry 2015; 5: e509.

52. Sutton MA, Wall NR, Aakalu GN, Schuman EM. Regulation of dendritic protein synthesis by miniature synaptic events. Science 2004; 304:1979-1983.

53. Sutton MA, Ito HT, Cressy P, Kempf C, Woo JC, Schuman EM. Miniature neurotransmission stabilizes synaptic function via tonic suppression of local dendritic protein synthesis. Cell 2006;125:785-799.

54. Nosyreva E, Szabla K, Autry AE, Ryazanov AG, Monteggia LM, Kavalali ET. Acute suppression of spontaneous neurotransmission drives synaptic potentiation. J Neurosci 2013;33:6990-7002.

55. Autry AE, Adachi M, Nosyreva E, Na ES, Los MF, Cheng PF, et al. NMDA receptor blockade at rest triggers rapid behavioural antidepressant responses. Nature 2011;475:91-95.

56. Gideons ES, Kavalali ET, Monteggia LM. Mechanisms underlying differential effectiveness of memantine and ketamine in rapid antidepressant responses. Proc Natl Acad Sci U S A 2014;111:8649-8654.

57. Newport DJ, Carpenter LL, McDonald WM, Potash JB, Tohen M, Nemeroff CB, et al. Ketamine and other NMDA antagonists: early clinical trials and possible mechanisms in depression. Am J Psychiatry 2015;172:950-966.

58. Zarate CA Jr, Singh JB, Quiroz JA, De Jesus G, Denicoff KK, Luckenbaugh DA, et al. A double-blind, placebo-controlled study of memantine in the treatment of major depression. Am J Psychiatry 2006; 
163:153-155.

59. Lenze EJ, Skidmore ER, Begley AE, Newcomer JW, Butters MA, Whyte EM. Memantine for late-life depression and apathy after a disabling medical event: a 12-week, double-blind placebo-controlled pilot study. Int J Geriatr Psychiatry 2012;27:974-980.

60. Zarate CA Jr, Mathews D, Ibrahim L, Chaves JF, Marquardt C, Ukoh $\mathrm{I}$, et al. A randomized trial of a low-trapping nonselective N-methylD-aspartate channel blocker in major depression. Biol Psychiatry 2013;74:257-264.

61. Sanacora G, Johnson MR, Khan A, Atkinson SD, Riesenberg RR, Schronen JP, et al. Adjunctive Lanicemine (AZD6765) in Patients with Major Depressive Disorder and History of Inadequate Response to Antidepressants: A Randomized, Placebo-Controlled Study. Neuropsychopharmacology 2017; 42: 844-853.

62. Zarate CA Jr, Brutsche N, Laje G, Luckenbaugh DA, Venkata SL, Ramamoorthy A, et al. Relationship of ketamine's plasma metabolites with response, diagnosis, and side effects in major depression. Biol Psychiatry 2012;72:331-338.

63. Zanos P, Moaddel R, Morris PJ, Georgiou P, Fischell J, Elmer GI, et al. NMDAR inhibition-independent antidepressant actions of ketamine metabolites. Nature 2016;533:481-486.

64. Yamaguchi JI, Toki H, Qu Y, Yang C, Koike H, Hashimoto K, et al. (2R,6R)-Hydroxynorketamine is not essential for the antidepressant actions of (R)-ketamine in mice. Neuropsychopharmacology 2018; 43:1900-1907.

65. Zarate CA Jr, Singh JB, Carlson PJ, Brutsche NE, Ameli R, Luckenbaugh DA, et al. A randomized trial of an N-methyl-D-aspartate antagonist in treatment-resistant major depression. Arch Gen Psychiatry 2006;63:856-864.

66. Petty F, Trivedi MH, Fulton M, Rush AJ. Benzodiazepines as antidepressants: does GABA play a role in depression? Biol Psychiatry 1995;38:578-591.

67. Murrough JW, Iosifescu DV, Chang LC, Al Jurdi RK, Green CE, Perez AM, et al. Antidepressant efficacy of ketamine in treatment-resistant major depression: a two-site randomized controlled trial. Am J Psychiatry 2013;170:1134-1142.

68. Diazgranados N, Ibrahim L, Brutsche NE, Newberg A, Kronstein P, Khalife S, et al. A randomized add-on trial of an N-methyl-D-aspartate antagonist in treatment-resistant bipolar depression. Arch Gen Psychiatry 2010;67:793-802.

69. Zarate CA Jr, Brutsche NE, Ibrahim L, Franco-Chaves J, Diazgranados N, Cravchik A, et al. Replication of ketamine's antidepressant efficacy in bipolar depression: a randomized controlled add-on trial. Biol Psychiatry 2012;71:939-946.

70. Sos P, Klirova M, Novak T, Kohutova B, Horacek J' Palenicek T. Relationship of ketamine's antidepressant and psychotomimetic effects in unipolar depression. Neuro Endocrinol Lett 2013;34:287-293.

71. Hu YD, Xiang YT, Fang JX, Zu S, Sha S, Shi H, et al. Single i.v. ketamine augmentation of newly initiated escitalopram for major depression: results from a randomized, placebo-controlled 4-week study. Psychol Med 2016;46:623-635.

72. Goldberg ME, Domsky R, Scaringe D, Hirsh R, Dotson J, Sharaf I, et al. Multi-day low dose ketamine infusion for the treatment of complex regional pain syndrome. Pain Physician 2005;8:175-179.

73. Lenze EJ, Farber NB, Kharasch E, Schweiger J, Yingling M, Olney J, et al. Ninety-six hour ketamine infusion with co-administered clonidine for treatment-resistant depression: A pilot randomised controlled trial. World J Biol Psychiatry 2016;17:230-238.

74. McGirr A, Berlim MT, Bond DJ, Fleck MP, Yatham LN, Lam RW. A systematic review and meta-analysis of randomized, double-blind, placebo-controlled trials of ketamine in the rapid treatment of major depressive episodes. Psychol Med 2015;45:693-704.

75. Fava M, Freeman MP, Flynn M, Judge H, Hoeppner BB, Cusin C, et al. Double-blind, placebo-controlled, dose-ranging trial of intravenous ketamine as adjunctive therapy in treatment-resistant depres- sion (TRD). Mol Psychiatry 2018 [Epub ahead of print].

76. Diamond PR, Farmery AD, Atkinson S, Haldar J, Williams N, Cowen PJ, et al. Ketamine infusions for treatment resistant depression: a series of 28 patients treated weekly or twice weekly in an ECT clinic. J Psychopharmacol 2014;28:536-544.

77. Ionescu DF, Bentley KH, Eikermann M, Taylor N, Akeju O, Swee $\mathrm{MB}$, et al. Repeat-dose ketamine augmentation for treatment-resistant depression with chronic suicidal ideation: A randomized, double blind, placebo controlled trial. J Affect Disord 2019;243:516-524.

78. Singh JB, Fedgchin M, Daly EJ, De Boer P, Cooper K, Lim P, et al. A Double-Blind, Randomized, Placebo-Controlled, Dose-Frequency Study of Intravenous Ketamine in Patients With Treatment-Resistant Depression. Am J Psychiatry 2016;173:816-826.

79. Phillips JL, Norris S, Talbot J, Birmingham M, Hatchard T, Ortiz A, et al. Single, Repeated, and Maintenance Ketamine Infusions for Treatment-Resistant Depression: A Randomized Controlled Trial. Am J Psychiatry 2019;176:401-409.

80. Weksler N, Ovadia L, Muati G, Stav A. Nasal ketamine for paediatric premedication. Can J Anaesth 1993;40:119-121.

81. Diaz JH. Intranasal ketamine preinduction of paediatric outpatients. Paediatr Anaesth 1997;7:273-278.

82. Opler LA, Opler MG, Arnsten AF. Ameliorating treatment-refractory depression with intranasal ketamine: potential NMDA receptor actions in the pain circuitry representing mental anguish. CNS Spectr 2016;21:12-22.

83. Lapidus KA, Levitch CF, Perez AM, Brallier JW, Parides MK, Soleimani $\mathrm{L}$, et al. A randomized controlled trial of intranasal ketamine in major depressive disorder. Biol Psychiatry 2014;76:970-976.

84. Daly EJ, Singh JB, Fedgchin M, Cooper K, Lim P, Shelton RC, et al. Efficacy and Safety of Intranasal Esketamine Adjunctive to Oral Antidepressant Therapy in Treatment-Resistant Depression: A Randomized Clinical Trial. JAMA Psychiatry 2018;75:139-148.

85. Daly EJ, Trivedi MH, Janik A, Li H, Zhang Y, Li X, et al. Efficacy of esketamine nasal spray plus oral antidepressant treatment for relapse prevention in patients with treatment-resistant depression: a randomized clinical trial. JAMA Psychiatry 2019 [Epub ahead of print]

86. Popova V, Daly EJ, Trivedi M, Cooper K, Lane R, Lim P, et al. Efficacy and safety of flexibly dosed esketamine nasal spray combined with a newly initiated oral antidepressant in treatment-resistant depression: a randomized double-blind active-controlled study. Am J Psychiatry 2019;176:428-438.

87. Ochs-Ross R, Daly EJ, Zhang Y, Lane R, Lim P, Foster K, et al. Efficacy and safety of esketamine nasal spray plus an oral antidepressant in elderly patients with treatment-resistant depression. Am J Geriatr Psychiatry 2019;27:S139-S140.

88. Sokero TP, Melartin TK, Rytsala HJ, Leskela US, Lestela-Mielonen PS, Isometsa ET. Suicidal ideation and attempts among psychiatric patients with major depressive disorder. J Clin Psychiatry 2003;64: 1094-1100.

89. De Berardis D, Fornaro M, Valchera A, Cavuto M, Perna G, Di Nicola $\mathrm{M}$, et al. Eradicating suicide at its roots: preclinical bases and clinical evidence of the efficacy of ketamine in the treatment of suicidal behaviors. Int J Mol Sci 2018;19.

90. Price RB, Mathew SJ. Does ketamine have anti-suicidal properties? Current status and future directions. CNS Drugs 2015;29:181-188.

91. Price RB, Iosifescu DV, Murrough JW, Chang LC, Al Jurdi RK, Iqbal SZ, et al. Effects of ketamine on explicit and implicit suicidal cognition: a randomized controlled trial in treatment-resistant depression. Depress Anxiety 2014;31:335-343.

92. Murrough JW, Soleimani L, DeWilde KE, Collins KA, Lapidus KA, Iacoviello BM, et al. Ketamine for rapid reduction of suicidal ideation: a randomized controlled trial. Psychol Med 2015;45:3571-3580.

93. Grunebaum MF, Galfalvy HC, Choo TH, Keilp JG, Moitra VK, Parris MS, et al. Ketamine for rapid reduction of suicidal thoughts in major depression: a midazolam-controlled randomized clinical trial. 
Am J Psychiatry 2018;175:327-335.

94. Canuso CM, Singh JB, Fedgchin M, Alphs L, Lane R, Lim P, et al. Efficacy and safety of intranasal esketamine for the rapid reduction of symptoms of depression and suicidality in patients at imminent risk for suicide: results of a double-blind, randomized, placebo-controlled study. Am J Psychiatry 2018;175:620-630.

95. Chen MH, Lin WC, Tu PC, Li CT, Bai YM, Tsai SJ, et al. Antidepressant and antisuicidal effects of ketamine on the functional connectivity of prefrontal cortex-related circuits in treatment-resistant depression: A double-blind, placebo-controlled, randomized, longitudinal resting fMRI study. J Affect Disord 2019;259:15-20.

96. Krystal JH, Karper LP, Seibyl JP, Freeman GK, Delaney R, Bremner JD, et al. Subanesthetic effects of the noncompetitive NMDA antagonist, ketamine, in humans. Psychotomimetic, perceptual, cognitive, and neuroendocrine responses. Arch Gen Psychiatry 1994;51:199-214.

97. Morgan CJ, Mofeez A, Brandner B, Bromley L, Curran HV. Acute effects of ketamine on memory systems and psychotic symptoms in healthy volunteers. Neuropsychopharmacology 2004;29:208-218.

98. Wan LB, Levitch CF, Perez AM, Brallier JW, Iosifescu DV, Chang LC, et al. Ketamine safety and tolerability in clinical trials for treatmentresistant depression. J Clin Psychiatry 2015;76:247-252.

99. Kishimoto T, Chawla JM, Hagi K, Zarate CA, Kane JM, Bauer M, et al. Single-dose infusion ketamine and non-ketamine N-methyl-d-aspartate receptor antagonists for unipolar and bipolar depression: a meta-analysis of efficacy, safety and time trajectories. Psychol Med 2016;46:1459-1472.

100. Fond G, Loundou A, Rabu C, Macgregor A, Lancon C, Brittner M, et al. Ketamine administration in depressive disorders: a systematic review and meta-analysis. Psychopharmacology (Berl) 2014;231:3663-3676.

101. Short B, Fong J, Galvez V, Shelker W, Loo CK. Side-effects associated with ketamine use in depression: a systematic review. Lancet Psychiatry 2018;5:65-78.

102. Anand A, Charney DS, Oren DA, Berman RM, Hu XS, Cappiello A, et al. Attenuation of the neuropsychiatric effects of ketamine with lamotrigine: support for hyperglutamatergic effects of N-methyl-D-aspartate receptor antagonists. Arch Gen Psychiatry 2000; 57: 270-276.

103. Huang MC, Chen LY, Chen CK, Lin SK. Potential benefit of lamotrigine in managing ketamine use disorder. Med Hypotheses 2016; 87: 97-100

104. Williams NR, Heifets BD, Blasey C, Sudheimer K, Pannu J, Pankow
$\mathrm{H}$, et al. Attenuation of antidepressant effects of ketamine by opioid receptor antagonism. Am J Psychiatry 2018;175:1205-1215.

105. Morgan CJ, Muetzelfeldt L, Curran HV. Consequences of chronic ketamine self-administration upon neurocognitive function and psychological wellbeing: a 1-year longitudinal study. Addiction 2010; 105:121-133.

106. Liu Y, Lin D, Wu B, Zhou W. Ketamine abuse potential and use disorder. Brain Res Bull 2016;126:68-73.

107. Sassano-Higgins S, Baron D, Juarez G, Esmaili N, Gold M. A review of ketamine abuse and diversion. Depress Anxiety 2016;33:718-727.

108. Li JH, Vicknasingam B, Cheung YW, Zhou W, Nurhidayat AW, Jarlais DC, et al. To use or not to use: an update on licit and illicit ketamine use. Subst Abuse Rehabil 2011;2:11-20.

109. Murrough JW, Burdick KE, Levitch CF, Perez AM, Brallier JW, Chang LC, et al. Neurocognitive effects of ketamine and association with antidepressant response in individuals with treatment-resistant depression: a randomized controlled trial. Neuropsychopharmacology 2015;40:1084-1090.

110. Gorlyn M, Keilp JG, Grunebaum MF, Taylor BP, Oquendo MA, Bruder GE, et al. Neuropsychological characteristics as predictors of SSRI treatment response in depressed subjects. J Neural Transm (Vienna) 2008;115:1213-1219.

111. Monteggia LM, Zarate C Jr. Antidepressant actions of ketamine: from molecular mechanisms to clinical practice. Curr Opin Neurobiol 2015;30:139-143.

112. Ionescu DF, Luckenbaugh DA, Niciu MJ, Richards EM, Slonena EE, Vande Voort JL, et al. Effect of baseline anxious depression on initial and sustained antidepressant response to ketamine. J Clin Psychiatry 2014;75:e932-938.

113. Salloum NC, Fava M, Freeman MP, Flynn M, Hoeppner B, Hock RS, et al. Efficacy of intravenous ketamine treatment in anxious versus nonanxious unipolar treatment-resistant depression. Depress Anxiety 2019;36:235-243.

114. Wilkinson ST, Wright D, Fasula MK, Fenton L, Griepp M, Ostroff $\mathrm{RB}$, et al. Cognitive behavior therapy may sustain antidepressant effects of intravenous Ketamine in treatment-resistant depression. Psychother Psychosom 2017;86:162-167.

115. Bahr R, Lopez A, Rey JA. Intranasal Esketamine (Spravato ${ }^{\mathrm{TM}}$ ) for use in treatment-resistant depression in conjunction with an oral antidepressant. P T 2019;44:340-375. 